\title{
Serological, genomic, and structural analyses of the major mite allergen Der p 23
}

\author{
Geoffrey A. Mueller ${ }^{a,}{ }^{,}$, Thomas A. Randall ${ }^{b}$, Jill Glesner ${ }^{c}$, Lars C. Pedersen ${ }^{a}$, Lalith Perera ${ }^{a}$, \\ Lori L. Edwards ${ }^{a}$, Eugene F. DeRose ${ }^{a}$, Martin D. Chapman ${ }^{c}$, Robert E. London ${ }^{a}$, and Anna \\ Pomés ${ }^{c}$ \\ ${ }^{a}$ Genome Integrity and Structural Biology Laboratory, National Institute of Environmental Health \\ Sciences, National Institutes of Health, Research Triangle Park, NC \\ ' Integrative Bioinformatics, National Institute of Environmental Health Sciences, National \\ Institutes of Health, Research Triangle Park, NC \\ 'INDOOR Biotechnologies, Inc. Charlottesville, VA
}

\section{Abstract}

Background-Der p 23 was recently identified in a European population as a major allergen and potentially a chitin binding protein.

Objective-This study sought to assess the importance of Der p 23 among other Dermatophagoides allergens in a North American population, and to determine the structure for functional characterization.

\begin{abstract}
Methods-IgE binding to Der p 23, Der p 1, Der p 2, Der p 5, Der p 7, and Der p 8 was measured by ELISA. RNA-seq data from D. pteronyssinus were compared as estimates of allergen expression levels. The structure was analyzed by X-ray crystallography and NMR.

Results-Despite a high prevalence of Der p 23, (75\% versus $87 \%$ and $79 \%$ for Der p 1 and Der $\mathrm{p} 2$, respectively), the anti-Der $\mathrm{p} 23 \mathrm{IgE}$ levels were relatively low. The patient response to the 6 allergens tested was variable $(n=47)$, but on average anti-Der $\mathrm{p} 1$ and anti-Der $\mathrm{p} 2$ together accounted for $85 \%$ of the specific IgE. In terms of abundance, the RNA expression level of Der $p$ 23 is the lowest of the major allergens, 30-fold less than and 7-fold less than Der p 2. The structure of Der p 23 is a small, globular protein stabilized by two disulfide bonds, which is structurally related to allergens such as Blo t 12 that contain carbohydrate binding domains that bind chitin. Functional assays failed to confirm chitin binding by Der $\mathrm{p} 23$.
\end{abstract}

Conclusions and Clinical Relevance-Der p 23 accounts for a small percentage of the IgE response to mite allergens, which is dominated by Der $\mathrm{p} 1$ and Der $\mathrm{p} 2$. The prevalence and amount of specific IgE to Der p 23 and Der p 2 are disproportionately high compared to the expressions of other Dermatophagoides allergens.

\footnotetext{
*Corresponding Author: mueller3@niehs.nih.gov, 111 T.W. Alexander Dr MD-MR01, Research Triangle Park, NC 27709. The authors have not conficts of intersest to declare.
} 


\section{Keywords}

Der p 23; Allergen; RNAseq; House Dust Mite

\section{Introduction}

In a recent U.S. survey, about $20 \%$ of the population had specific IgE antibodies to the house dust mite (HDM) species Dermatophagoides pteronyssinus and/or Dermatophagoides farinae [1]. In fact, only sensitization to rye grass was more common. Compared to outdoor allergens, sensitization to indoor allergens is more commonly associated with asthma, and more specifically extrinsic asthma [2]. More than $80 \%$ of asthmatic patients demonstrate immediate hypersensitivity to allergens of the house dust mites [3, 4]. More than 30 groups of allergens from Dermatophagoides spp. are presently reported in the official Allergen Nomenclature database from the World Health Organization/International Union of Immunological Societies (WHO/IUIS) (www.allergen.org).

In the first study on Der p 23, 74\% of 347 European HDM allergic patients had IgE antibodies to Der p 23 [5]. Further studies, also performed in a European population, concluded that Der $\mathrm{p} 23$-specific IgE antibodies were elevated in children with asthma compared to non-asthmatics [6]. In house dust mite, Der p 23 was found in the fecal pellets, similar to other mite allergens. However, it was not particularly abundant and eluted slowly from fecal particles compared to Der $\mathrm{p} 1$ and Der $\mathrm{p} 2$. The protein was identified from sequential comparisons to contain a carbohydrate binding domain (CBD, specifically PFAM:CBM_14). Closely related proteins are also known as peritrophin-A binding domains, and indeed, immunogold staining confirmed the localization of Der $\mathrm{p} 23$ to the peritrophic matrix [5]. Other allergens that contain a CBD are groups 15 and 18 from Dermatophagoides spp. [7] and, group 12 from Blomia tropicalis [8]. Resch and Vrtala mention as unpublished observations that Der $\mathrm{p} 15$ and Der $\mathrm{p} 18$ did not cross-react with Der p 23, further confirming that group 23 is a distinct allergen [5]. Similarly, anti-Blo t 12 antibodies did not react with any molecule present in D. pteronyssinus extracts [9]. At present, there is little structural information to understand the immunochemistry of these allergens. We therefore sought to determine the three-dimensional structure of Der p 23 and perform a comparative analysis with other Dermatophagoides pteronyssinus allergens in a North American population.

Blo $t 2$ is known to be a chitin binding protein and chitin is a potent stimulant of the innate immune system [9-11]. In fact, using a mouse model, chitin enhances the production of IgE antibodies in a manner dependent on the affinity of the Blo t 12 isoform for chitin [9]. These observations motivated several experiments to test if Der p 23 may have a similar binding capacity for chitin. Further, human chitinases are upregulated in asthmatics indicating that the innate defense against chitin may be important in sensitization and the exacerbation of allergic disease $[12,13]$. 


\section{Methods}

\section{Expression and Purification}

The Der p 23 gene sequence encoding residues 24-70 was synthesized (Genscript, NJ, USA). Residue 70 is the C-terminus of the reported Der $\mathrm{p} 23$ sequence and follows the residue numbering of Banerjee et al for ease of comparison [14]. Inclusion of these residues was based on primary sequence analysis suggesting that the $\mathrm{N}$-terminal 23 residues were largely unstructured and previous studies indicating that deletion of residues 1-31 did not affect IgE recognition [14]. For more information, see Figure S1. We refer to this construct as rDer $\mathrm{p} 23$.

rDer p 23 was expressed solubly in Rosetta 2 DE3 pLacI cells using an MBP N-terminal affinity fusion (vector pDEST-566). For expression, cells were grown in 1-2 liters of LB or $2 \mathrm{xYT}$ media for overnight growth at $37 \mathrm{C}$ with shaking at $250 \mathrm{RPM}$. The cells were pelleted and resuspended in twice the amount of fresh media, allowed to equilibrate at $18 \mathrm{C}$ for 1 hour, and then induced with $0.4 \mathrm{mM}$ IPTG for 18-24 hours. The cells were lysed by sonication on ice for 3 minutes at 50\% power and 50\% duty cycle in $50 \mathrm{mM}$ HEPES pH 7.4, $100 \mathrm{mM} \mathrm{NaCl}$ with 'Complete' EDTA-free protease inhibitors (Roche). The lysate was cleared by centrifugation and flowed over two $5 \mathrm{ml}$ amylose columns in series. Fractions containing MBP-rDer p 23 were pooled and cleaved with tobacco etch virus (TEV) protease, leaving three extra residues (Ser-Phe-Thr) at the N-terminus of rDer $\mathrm{p}$ 23. Following cleavage, rDer $\mathrm{p} 23$ was further purified by size exclusion chromatography using a Superdex75 column equilibrated with PBS. This construct was used for all studies in this paper. For the NMR studies with isotopic labeling, rDer $\mathrm{p} 23$ failed to express in the common M9 minimal media, so enriched isotopic algal lysates supplemented the M9, using $1 \mathrm{~g} / \mathrm{l}$ of either $\mathrm{U}^{-15} \mathrm{~N}$ or $\mathrm{U}_{-13}{ }^{13},{ }^{15} \mathrm{~N}$ Isogro media from Isotec (Miami, OH). NMR experiments were performed in $50 \%$ PBS, $10 \% \mathrm{D}_{2} \mathrm{O}$.

\section{Patients}

Plasma from 47 mite allergic patients were obtained from PlasmaLab International (Everett, Wash), which operates in full compliance of US Food and Drug Administration. Informed donor's consent was obtained from each subject before the first donation. Most patients had allergic rhinitis $(n=44)$, and a few had atopic dermatitis $(n=3)$. Total $\operatorname{IgE}$ was measured by ImmunoCAP. Plasma were selected because they had mite-specific IgE by ImmunoCAP (class $2, \mathrm{n}=5$; class 3, $\mathrm{n}=6$; class $4, \mathrm{n}=9$; class $5, \mathrm{n}=8$; class $6, \mathrm{n}=8$; total of $\mathrm{n}=36$ ) and/or by Multiplex IgE binding array (Der $\mathrm{f} 1$, Der $\mathrm{p} 1$, and Der $\mathrm{p} 2 ; \mathrm{n}=11$ with low $\operatorname{IgE}$ levels to Der p $1(1.9 \pm 2.4 \mathrm{IU} / \mathrm{mL})$ and Der p $2(2.4 \pm 4.3 \mathrm{IU} / \mathrm{mL}))$ [15]. The subgroup of 11 patients were originally identified as cat allergic with high levels IgE to Fel d 1 (179.7 \pm $273.9 \mathrm{IU} / \mathrm{mL}$ ). Plasma IgE reactivity to mite allergens was measured by either ImmunoCAP $(848 \pm 1,615 \mathrm{kU} / \mathrm{L}$, range of $44-8,605 \mathrm{kU} / \mathrm{L} ; \mathrm{n}=43)$ or Multiplex Array $(672 \pm 232$ $\mathrm{IU} / \mathrm{mL}$, range of $460-1,001 \mathrm{IU} / \mathrm{mL} ; \mathrm{n}=4)$. Negative controls were either nonallergic $(\mathrm{n}=$ 3 ) or nonallergic to mite ( $\operatorname{IgE}<0.35 \mathrm{kU} / \mathrm{L}$ ) but allergic to various other allergens: cat, dog, birch, timothy grass and/or cockroach $(n=3)$. 


\section{Measurement of specific IgE to six dust mite allergens}

Mite IgE positive plasma $(n=47)$ were assayed by ELISA in parallel on the same day for IgE antibodies to 5 allergens (nDer p 1, nDer p 2, rDer p 5, rDer p 7 and rDer $\mathrm{p} 23$ ), and separately for IgE to rDer $p 8$ [16]. Allergens used for IgE binding assays were natural Der $p$ 1, Der p 2, recombinant Der p 5 and Der p 8 expressed in E. coli, and recombinant Der p 7 expressed in Pichia pastoris [17-21]. Microplates were coated with the allergen $(10 \mu \mathrm{g} / \mathrm{ml})$. Most plasma were added at 1:2 and 1:10 dilutions, and plasma with high titers for Der $\mathrm{p} 1$ and Der $\mathrm{p} 2$ were re-tested at 1:20 and 1:50 $(\mathrm{n}=3)$. Bound $\operatorname{IgE}$ was detected using biotinylated goat anti-human IgE (KPL, Gaithersburg, MD). An IgE standard curve was obtained with anti-Der p $2 \mathrm{mAb} a \mathrm{Dpx}$, nDer p 2, and the chimeric antibody 2B12-IgE, with a range of $255-0.249 \mathrm{IU} / \mathrm{mL}$ [22]. The 2B12-IgE antibody was standardized against WHO IgE standard 501/75 and the Phadia ImmunoCAP standard. IgE values were considered positive if equal to or larger than the cut-off calculated as the arithmetic mean of negative controls plus 3 times the standard deviation. The sensitivity of the least sensitive test was selected for each allergen (thresholds $0.42-0.63 \mathrm{IU} / \mathrm{mL}$ ). The negative controls were up to 4 sera/plasma from atopic patients non-allergic to mite $(n=2)$ and/or from non-atopic patients $(\mathrm{n}=3)$.

\section{RNA-seq Analyses}

D. pteronyssinus RNA was kindly provided by Larry Arlian, Wright State University. Briefly, D. pteronyssinus was cultured at room temperature on Diet A as described [23, 24]. RNA from D. pteronyssinus was isolated by standard procedures using Direct-zol RNA MiniPrep according to the manufacturer instructions (Zymo Research). RNA-seq analysis produced 317,387,496 paired end reads of 126 base pairs each. A de novo assembly from Trinity (Trinityrnaseq_r20131110) of 39861 transcripts was processed using RSEM to quantitate the expression levels of these transcripts in fragments per kilobase of transcript per million mapped reads (FPKM) [25, 26]. Here the FPKM values are reported for Der p 1, Der p 2, Der p 5, Der p 7, Der p 8, and Der p 23. A detailed description of the methods and a full analysis of the predicted proteome is intended for publication elsewhere.

\section{Crystallization and NMR Studies}

Structural data for rDer p 23 determined crystallographically was deposited in the Protein Data Bank with the PDB code 4ZCE; data quality statistics related to crystallography are shown in Table S1. Very large crystals were fortuitously discovered in a $4 \mathrm{mg} / \mathrm{ml}$ sample of rDer p 23 that had been stored in 50\% PBS at $4^{\circ} \mathrm{C}$ for more than two months. Multiple crystals were large enough to be visualized unmagnified. For data collection, crystals were directly transferred to 50\% PBS buffer and $26 \%$ ethylene glycol and flash frozen in liquid nitrogen. Data was collected on a 007HF rotating anode equipped with VariMaxHF mirrors and a Saturn944 CCD detector (Rigaku). Sulfur SAD phasing utilizing the eight cysteines present in the asymmetric unit was used to solve the phase problem. To obtain sufficient redundancy for phasing, data from two crystals were merged together in HKL3000 [27]. SHELXD [28] was used to determine the positions of the sulfur atoms, mlphare [29] was used for phasing, and ARP/Warp [30] was used to build an initial model of rDer p 23. A high-resolution data set at $1.55 \AA$ was generated from data collected off the second crystal 
alone. The ARP/Warp model was then used as the starting model to refine against the high resolution data in Phenix [31] with manual model building in Coot [32]. The final model has two molecules of rDer p 23 in the asymmetric unit and shows good geometry as analyzed with Molprobity [33]. NMR assignments were made using standard triple resonance experiments and protocols on Varian INVOVA Unity+ 500 and $600 \mathrm{MHz}$ spectrometers, similar to those performed previously with Cat $r 1$ [34].

\section{Structure Modeling of Der $\mathbf{f} 23$}

The sequence of Der f 23 was aligned with Der p 23 using the sequence alignment tool, TCoffee [35]. Using the X-ray crystal structure of rDer p 23 as the template, the starting structures were constructed with the program, Coot [32]. The starting structures were then dynamically energy minimized by running Generalized Born (GB) simulations using the Sander module of the program, Amber, version 14 (Amber.14). All GB simulations for structure optimizations were carried out using the FF14SB force field of Amber.14 [36]. The models of $D$. farinae CBD domains were colored according to the biochemical similarity of the residues that align with Der p 23. The property distance matrix [37] was used to assess the degree of similarity and color scheme was adapted from the nine-color scale used by the program CONSURF to compare evolutionary relationships [19, 38].

\section{Results}

\section{IgE binding to rDer $p 23$ in comparison to other mite allergens}

The prevalences of specific IgE (sIgE) to each of the 6 dust mite allergens was highest for Der p 1 (87\%), followed by Der p 2 (79\%), Der p 23 (75\%), Der p 8 (53\%), Der p 5 (47 $\%)$ and Der p $7(23 \%)(n=47)$ (Fig. 1, Table 1). The IgE prevalence to Der p 1 and/or Der $p$ 2 was $96 \%$. The highest levels of sIgE were directed against Der $\mathrm{p} 1$ and Der $\mathrm{p} 2$ (the geometric means were 4.4 and $5.4 \mathrm{IU} / \mathrm{mL}$, respectively), followed by Der p $23(1.4 \mathrm{IU} / \mathrm{mL})$, Der p $5(0.8 \mathrm{IU} / \mathrm{mL})$, Der p $8(0.7 \mathrm{IU} / \mathrm{mL})$ and Der p $7(0.6 \mathrm{IU} / \mathrm{mL})$. The data confirms a moderately high prevalence of sIgE to Der $\mathrm{p} 23$, however, the levels of sIgE were $\sim 5$-fold lower than to Der $\mathrm{p} 1$ or Der $\mathrm{p} 2$.

The specific IgE data were further analyzed to compare the proportion of $\operatorname{IgE}$ directed against the six allergens tested. For each patient, the percentage of specific IgE against each allergen was compared to the sum of specific IgE to the 6 allergens tested, abbreviated S6sIgE (Figure $2 \mathrm{~A} \& \mathrm{~B}$ ). Patients were separated in two groups according to the S6-sIgE being above (Figure $2 \mathrm{~A}, \mathrm{C}$ ) or below (Figure $2 \mathrm{~B}, \mathrm{D})$ the median of S6-sIgE $(20.5 \mathrm{IU} / \mathrm{mL}$ ). The box plots for the percent sIgE of the two patient groups show that the higher responders have disproportionately higher levels of anti-Der $\mathrm{p} 2 \operatorname{IgE}$ (Figure $2 \mathrm{C} \& \mathrm{D}$ ). With the exception of Der $\mathrm{p} 2$, the relative proportion of IgE against the other allergens was very similar in the two groups (Figure 2). Despite the dominance of IgE to Der $\mathrm{p} 1$ and Der $\mathrm{p} 2$, a variability in the responses per patient was also observed (e.g. patient \#3 versus \#4 in Figure $2 \mathrm{~A})$. In addition, there were only a few patients that had higher levels of anti-Der $\mathrm{p} 23 \mathrm{IgE}$ than either anti-Der p 1 or anti-Der p 2 (15\% and 13\%, respectively). Examples can be identified in Figure 2A where patients \#4, \#14, and \#15 have a very low proportion of anti- 
Der p 1 IgE. Similarly in Figure 2B patient \#18 has a very high proportion of anti-Der p 23 $\mathrm{IgE}$ that exceeds the amount of anti-Der $\mathrm{p} 2 \mathrm{IgE}$.

Overall, the sum of IgE against Der p 1 and Der p $2(3,127.3 \mathrm{IU} / \mathrm{mL})$ accounted for a large proportion $(84.6 \%)$ of the S6-sIgE $(3,696.1 \mathrm{IU} / \mathrm{mL} ; \mathrm{n}=47)$ (Table 1). Addition of IgE against Der p 23 to IgE against Der p 1 and Der $\mathrm{p} 2$ only added $4.4 \%$ to that percentage, up to a total of $89 \%$. The correlation between total IgE and the S6-sIgE was positive $(r=0.43, n$ =47). The low value reflects that not all of the patient IgE was directed against the six allergens tested. The S6-sIgE correlated best with specific IgE reactivity to Der p 2 ( $\mathrm{r}=0.94)$, and was followed by Der p 23 (r=0.83), Der p 1, (r=0.80), Der p 5 (r=0.64), Der p 8 $(\mathrm{r}=0.55)$, and Der $\mathrm{p} 7(\mathrm{r}=0.40)$. Note that because the $\operatorname{IgE}$ titers in Figure 1 spanned 4 orders of magnitude, the correlations were calculated using the logarithm of the sIgE values so that the data was not biased towards the highest responders. For the 36 patients for whom data were available, the mite immuno-CAP score correlated with the S6-sIgE ( $r=0.67$, Figure $\mathrm{S} 2$ ). This analysis excluded the 11 patients with low IgE titers to Der $\mathrm{p} 1$ and Der $\mathrm{p} 2$. The highest geometric mean (g.m.) of the S6-IgE was for plasma with a CAP score of 6 (g.m. $127.3 \mathrm{IU} / \mathrm{mL}$ ), followed by $4-5$ (g.m. 48.0 and $37.6 \mathrm{IU} / \mathrm{mL}$ ) and 2-3 (g.m. 7.1 and $5.3 \mathrm{IU} /$ $\mathrm{mL})$.

\section{Does Abundance Correlate with IgE Response?}

The possibility that allergen abundance may account for the differences in the IgE response was examined with RNA-seq data from $D$. pteronyssinus, assuming the RNA-seq levels correlate with human exposure. Der p 23 was reported to be a low abundance protein relative to other major dust mite allergens [5]. From the D. pteronyssinus RNA-seq data, the level of Der $\mathrm{p} 23$ transcript appears to correlate with the reported protein abundance relative to Der $\mathrm{p} 1$ and Der $\mathrm{p} 2$ (Figure3A and 3B) [5]. The level of Der p 23 expression is 30-fold less than Der p 1, and 7-fold less than Der p 2. As an aside, similar relative levels of expression are reported for the corresponding D. farinae allergens [39]. Figure 3 A\&B displays the expression level in relation to the prevalence and percent sIgE (respectively) reported herein. In Figure $3 \mathrm{C} \& \mathrm{D}$, the ratio of the prevalence and percent $\operatorname{sIgE}$ to the expression level is compared, respectively. From Figure 3C it is apparent that the number of mite allergic patients specifically recognizing Der $\mathrm{p} 23$, followed by Der $\mathrm{p} 5$, is disproportionately high compared to the expression level. Similarly in Figure 3D, the relative percentage of Der $\mathrm{p} 2$ specific IgE, followed by Der $\mathrm{p} 23$, is higher than would be expected if there was a simple linear correlation between expression level and percent sIgE.

\section{Crystal Structure}

The structure of rDer p 23 (residues 24-70) was determined by X-ray crystallography at $1.55 \AA$ resolution. Figure 4A shows that the structure contains two anti-parallel $\beta$-sheets, one composed of $\beta$-strands $1,2, \& 3$ and a smaller sheet with two short strands, $4 \& 5$. The two sheets appear to be held together via two primary interactions. First, there is a conserved disulfide bond between Cys56 and Cys69, and second there is an aromatic stacking interaction between Phe43 and Trp62 that was common in homologous mite proteins modeled for this study. Some of the modeled proteins contain a Trp residue interacting with a Phe or Tyr similar to the pattern observed in Der p 23 (Figure 4B). Alternatively, many 
appear to utilize smaller aromatic sidechains at both positions, with a Phe or Tyr at either spot creating a similar interface (data not shown).

A search of the protein database for structurally similar proteins revealed two other protein structures that aligned well with Der p 23: tachychitin (Figure 4C) and Blo t 12 (Figure 4D) [40, 41]. Blo t 12 adopts a similar fold and a similar disulfide bonding pattern, however, it contains two additional $\beta$ strands at the amino-terminus. As indicated by a structural and sequential comparison (Figure S1), the extra Blo t 12 strands align poorly with Der p 23 . Der $\mathrm{p} 23$ is not predicted to have any additional secondary structure based on primary sequence predictions. This is readily apparent in Figure $\mathrm{S} 1$ where the N-terminal 23 residues are primarily repeated hydrophilic residues. An alignment of Der p 23 with Blo t 12, Der p 15 , and Der p 18 indicates that the sequences are only $26 \%, 28 \%$, and $24 \%$ identical, respectively, while three variants of Der f 15 are between 36 and $48 \%$ identical in sequence to Blo t 12. The extra strands in Blo t 12 represent a substantial difference between the two structures, and confirm that Blo t 12 is most closely related to the Dermatophagoides group 15 allergens.

The smaller $\beta$-sheet in tachychitin was reported to be similar to a hevein domain that is found in the latex allergen Hev b 6 that is known to bind chitin [42]. A comparison of a hevein domain bound to a chitin fragment ( $\beta-1,4$ linked tri-N-acetyl glucosamine) with Der p 23 and tachychitin is shown in Figure 4E [43]. The data shows that the backbone atoms and the disulfide bond of Der p 23 and tachychitin align well with hevein. However, the tight turn in these two molecules contains extra amino acids that would clearly clash with the bound chitin fragment if it bound in a similar manner to Der $\mathrm{p} 23$ or tachychitin. Figure $4 \mathrm{~F}$ shows how the hevein domain interacts with chitin via two tryptophan residues that are angled to accommodate two $\beta-1,4$ linked sugar moieties and a glutamate that appears to provide the specificity for the $\mathrm{N}$-acetyl group. None of these residues are present in either Der p 23 or tachychitin, rendering it unlikely that a similar mechanism of chitin binding is present in these molecules. Experiments with synthetic chitin beads (Figure S3), shrimp chitin (data not shown), $\beta-1,4$ linked di-N-acetyl glucosamine (Figure S4), and other saccharides (Figure S5) failed to detect binding to Der $\mathrm{p} 23$. In addition, tachychitin has antibacterial activity. However, this activity was not observed in an assay performed as reported for tachychitin (data not shown) [42].

\section{NMR comparisons and DTT treatment}

NMR assignments were obtained for 41 of the 43 residues in the predicted structural domain of Der p 23. The assignments are annotated on the ${ }^{1} \mathrm{H}^{1}{ }^{15} \mathrm{~N}$ HSQC spectra in Figure 5A, and the full assignment information was deposited in the BioMagResBank, accession \#26562. The similarity between the solution and crystal forms was verified using the chemical shifts of backbone atoms, which were used to accurately predict the protein backbone phi and psi angles of the crystal structure (Figure S6) [44]. There is a clear strong correlation between the solution NMR and crystal structure values of phi and psi, 0.88 and 0.99 respectively. Further verification of the structure can be found in some of the rare chemical shifts that can only be explained by specific structural features. For example, the amide proton of Thr68 has a rare upfield shift of $6.2 \mathrm{ppm}$ (usually $8.24+/-0.62$ ) [45], which can be explained by 
the positioning of this hydrogen atom in the plane of the Trp62 aromatic ring. Overall, the conclusion is that the molecule in solution very closely resembles the monomer in the crystal.

In contrast to Der p 23 and Blo t 12, tachychitin has 4 disulfide bonds, two of which align with the two found in the Der p 23 crystal structure between Cys 27 and Cys46, and between Cys56 and Cys69. The presence of the disulfide bonds could be verified in solution from the $\mathrm{C} \beta$ chemical shifts of the cysteine residues. The mean for reduced cysteines is 28.4 and the mean for oxidized cysteines in a disulfide bond is 40.7 [46]. In Der p 23 the values were all closer to 40.7, confirming the presence of disulfide bonds: $\mathrm{Cys}_{27} \delta_{\mathrm{C} \beta}=44.0$, Cys $46 \delta_{\mathrm{C} \beta}$ $=48.4$, Cys56 $\delta_{\mathrm{C} \beta}=37.6$, and Cys $69 \delta_{\mathrm{C} \beta}=43.4 \mathrm{ppm}$.

A proposed strategy for creating hypoallergens is to disrupt stabilizing disulfide bonds [47, 48]. The importance of the disulfide bonds in Der $\mathrm{p} 23$ was evaluated by adding the reducing agent DTT $(1 \mathrm{mM})$ and observing the effect on the ${ }^{1} \mathrm{H}^{-}{ }^{15} \mathrm{~N}$ NMR signals. A slow disappearance of all the resonances was observed over the course of 8 hours (Figure 5B) without a concomitant rise in peaks characteristic of unfolded protein nor was there obvious precipitate in the sample tube. The results indicate that upon reduction, Der p 23 is destabilized and forms large soluble aggregates. Secondarily, the long time course indicated that the stability of Der p 23 is not completely dependent on the disulfide bonds.

\section{Modeling Der f 23}

The recent publication of the related $D$. farinae genome [39] prompted us to investigate if a related Der $\mathrm{f} 23$ allergen would be cross-reactive. Figure 6 shows surface representations of the models, color-coded with respect to the biochemical similarity of the residues to Der $p$ 23 (Figure 6, grey), as described in the methods. The coloring in Figure 6 (Der f 23) reveals the high similarity in residue identity (87\%) and predicted surface shape between Der f 23 and Der $\mathrm{p} 23$. To illustrate the size of an antibody epitope in this figure, epitopes usually bury between 600 and $900 \AA^{2}$ [49], which would correspond to a circle (if perfectly flat) between 28 and $34 \AA$ in diameter. The double arrow in the figure is scaled to $28 \AA$. While theoretical, the suggestion is that antibodies against group 23 allergens will cross-react between Dermatophagoides spp.

\section{Discussion}

The sequence of Der p 23 aligns with many proteins in available databases that contain one or more copies of the CBD. Despite the fact that CBDs appear to be very common, there is little structural information about these motifs. The structure of Der p 23 was found to be similar to tachychitin from the horseshoe crab Tachypleus tridentatus [42]. Whereas tachychitin has antimicrobial activity, this activity could not be demonstrated for Der $\mathrm{p} 23$. The proteins are distantly related in sequence and most likely have different functions. The latex allergen Hev b 6, also known as hevein, is similar to tachychitin, and binds chitin [50]. However chitin binding could not be detected for Der $\mathrm{p} 23$ using chitin beads, shrimpderived chitin, or to the basic saccharides comprising chitin, by NMR (Figures S3, S4, \& S5). This result is consistent with the observation that the small $\beta$-sheet in Der p 23, while similar to hevein, is unlikely to bind polysaccharides in the same manner. A similar 
conclusion was drawn from a comparative structural analysis with tachychitin. In the original description of chitin binding by tachychitin, the protein was found to precipitate with chitin but did not elute upon addition of high salt or various polysaccharides, possibly indicating that it was not the sugar moieties that bound tachychitin to chitin [42]. In fact, very few protein components of the peritrophic matrix elute in physiological buffers and frequently require harsher treatments to elute [51], similar to what was observed for Der $p$ 23 [5]. The data on the lack of chitin polysaccharide binding by Der p 23 found here is consistent with these reported experimental observations. The results suggest that the Der $\mathrm{p}$ 23 is unlikely to enhance an IgE response upon addition of chitin in a manner similar to Blo t 12 [9].

Several fragments and hypoallergenic forms of Der p 23 were recently studied by Banerjee et al [14]. The fragments were compared for IgE reactivity and the IgE binding to fragment P3 containing residues $32-70$ was comparable to the full length construct. P3 is smaller than rDer $\mathrm{p} 23$ used in the present study, which contains residues $24-70$. The missing $\mathrm{N}$-terminal residues from P3 (24-31) form a loop with a disulfide bond between Cys27 and Cys46.

Although this bond would be absent in the P3 fragment, the $\beta$-sheets and the secondary structure of the domain should be retained. The researchers further tested variants of P3: P4 (32-60), P5 (42-70), and P6 (32-70, with all Cys replaced by Ser). All of these fragments showed greatly reduced IgE binding. An examination of the Der p 23 structure shows that P4 lacks the smaller $\beta$-sheet, P5 has lost $\beta$-strand 1, and P6 cannot form the Cys56-Cys69 disulfide. All of these mutations appear to be structurally destabilizing, similar to the DTT disulfide reduction results, which likely explains the decreased IgE binding. Fusion proteins with P4, P5, and P6 appear promising as hypoallergens [14].

Der p 1, Der p 2 and Der p 23 were major allergens in the group of mite allergic patients tested (prevalences of IgE reactivity above 50\%). As expected, Der p 1 or Der p 2 were recognized by most of the patient population ( $87 \%$ and $79 \%$, respectively), followed closely by Der p 23 (75\%). The prevalence of Der p 23-sensitized patients is higher than that reported in a recent European survey: 59\% among non-asthmatics and $71 \%$ among asthmatics [6]. Regarding the other allergens analyzed, Der p 5, Der p 7 and Der p 8 were minor, with Der p 5 and Der $\mathrm{p} 7$ having similar prevalences to the ones previously reported in Europe and Australia, and Der p 8 slightly higher [19, 52-54]. When considered in combination, sIgE to Der $\mathrm{p} 1$ and Der $\mathrm{p} 2$ correctly diagnosed $96 \%$ of mite allergic patients, and when combined with Der $\mathrm{p} 23$ there was no further improvement. This prevalence of IgE sensitization is only slightly higher than the one reported in a European study for Der $\mathrm{p}$ 1 and Der p 2 combined (89\%), and adding Der p 23 increased the percentage to 92\% because a few patients were uniquely sensitized to Der $\mathrm{p} 23$ [6]. It is tempting to speculate that, since mite extract is presumably a poor source of Der $\mathrm{p} 23$, the patient selection based on mite extracts might underestimate the importance of Der $\mathrm{p} 23$. However, since Der $\mathrm{p} 1$ and Der $\mathrm{p} 2$ are major allergens and IgE reactivity to either one or both accounts for most of the dust mite allergic patients (96\%), it is expected that most mite allergic patients, reactive or not to Der p 23, will be identified by the other major allergens. In fact, the previous two studies reporting prevalences of sensitization to Der $\mathrm{p} 23$, were also based on patients selected by their reactivity to mite extracts, and their prevalences were quite similar to the one reported here for Der p $23[5,6]$. 
As an important consideration, the RNA-seq levels of allergens are not necessarily a direct measure of human exposure to those allergens. The ratio of Der $\mathrm{p} 1$ expression to Der $\mathrm{p} 2$ was 7 fold and Der $p 1$ to Der $p 23$ was 30 fold. In general, there is usually twice the amount of Der $\mathrm{p} 1$ compared to Der $\mathrm{p} 2$ in house dust [55] so clearly other factors influence exposure. Weghofer et al report that Der p 23 is considerably less abundant than Der p 2 in house dust but did not provide a numeric value [5]. Nevertheless, relative values of RNA expression provide an estimate of the trend in allergen abundance, and support the contention that the immune response to Der $\mathrm{p} 23$ is not proportional to its abundance. Therefore other factors likely contribute to the high sensitization levels.

In terms of percentage of allergen-specific IgE versus the sum of $\operatorname{IgE}$ responses to each of the six allergens, Der $\mathrm{p} 1$ and Der $\mathrm{p} 2$ accounted for most of the response (85\%), and Der $\mathrm{p}$ 23 contributed only a small proportion (4\%). However, the amount of Der p 23-specific IgE was disproportionately large relative to the low RNA expression levels as compared to the other allergens. While Der $\mathrm{p} 1$ and Der $\mathrm{p} 2$ dominated the IgE response on average, there is patient variability in the individual responses, suggesting that molecular diagnostics may be useful in formulating individualized immunotherapy with recombinant allergens. Analysis of the ratios of RNA-seq abundance versus prevalence of IgE sensitization, led to similar conclusions: the antibody response is not linear with respect to RNA-seq abundance of allergens in the mite, which presumably relates to environmental exposure. Understanding the reasons for this disproportionate response may improve our knowledge of how the human immune system consistently selects certain proteins for developing a Th2 response.

\section{Supplementary Material}

Refer to Web version on PubMed Central for supplementary material.

\section{Acknowledgements}

Research in this publication was supported in part by Research Project Number Z01- ES102885-01 to REL, and ZIA- ES102645 to LCP in the Intramural Research Program of the National Institute of Environmental Health Sciences, National Institutes of Health, and in part by the National Institute of Allergy and Infectious Diseases of the National Institutes of Health under Award Number R01AI077653 (AP and MDC). The content is solely the responsibility of the authors and does not necessarily represent the official views of the National Institutes of Health. The authors thank Mr. Aaron Manning for help in protein purification, and Marjorie S. Morgan, S. Dean Rider, Jr., DiAnn L. Vyszenski-Moher, and Larry G. Arlian from Wright State University for providing the $D$. pteronyssinus RNA. The authors also thank the NIH Intramural Sequencing Center, Comparative Sequence Group for expert technical assistance with high-throughput sequencing.

\section{Abbreviations}

$\begin{array}{ll}\text { HDM } & \text { House Dust Mite } \\ \text { CBD } & \text { Carbohydrate Binding Domain } \\ \text { SIgE } & \text { Specific IgE } \\ \text { S6-sIgE } & \text { Sum of the sIgE to the six allergens tested } \\ \text { FPKM } & \text { Fragments per kilobase of transcript per million mapped reads. A relative } \\ & \text { measure of RNA transcription }\end{array}$




\section{References}

1. Salo PM, Arbes SJ, Jaramillo R, Calatroni A, Weir CH, Sever ML, et al. Prevalence of allergic sensitization in the United States: Results from the National Health and Nutrition Examination Survey (NHANES) 2005-2006. J Allergy Clin Immun. 2014; 134(2):350-359. [PubMed: 24522093]

2. Salo PM, Arbes SJ, Crockett PW, Thorne PS, Cohn RD, Zeldin DC. Exposure to multiple indoor allergens in US homes and its relationship to asthma. J Allergy Clin Immun. 2008; 121(3):678-684. [PubMed: 18255132]

3. Nelson RP, DiNicolo R, FernandezCaldas E, Seleznick MJ, Lockey RF, Good RA. Allergenspecific IgE levels and mite allergen exposure in children with acute asthma first seen in an emergency department and in nonasthmatic control subjects. J Allergy Clin Immun. 1996; 98(2): 258-263. [PubMed: 8757201]

4. Platts-Mills TA, Vervloet D, Thomas WR, Aalberse RC, Chapman MD. Indoor allergens and asthma: report of the Third International Workshop. J Allergy Clin Immunol. 1997; 100(6 Pt 1):S2S24. [PubMed: 9438476]

5. Weghofer M, Grote M, Resch Y, Casset A, Kneidinger M, Kopec J, et al. Identification of Der p 23, a Peritrophin-like Protein, as a New Major Dermatophagoides pteronyssinus Allergen Associated with the Peritrophic Matrix of Mite Fecal Pellets. J Immunol. 2013; 190(7):3059-3067. [PubMed: 23460742]

6. Resch Y, Michel S, Kabesch M, Lupinek C, Valenta R, Vrtala S. Different IgE recognition of mite allergen components in asthmatic and nonasthmatic children. J Allergy Clin Immunol. 2015; 136:1083-1091. [PubMed: 25956509]

7. O'neil SE, Heinrich TK, Hales BJ, Hazell LA, Holt DC, Fischer K, et al. The chitinase allergens Der p 15 and Der p 18 from Dermatophagoides pteronyssinus. Clinical and Experimental Allergy. 2006; 36(6):831-839. [PubMed: 16776685]

8. Puerta L, Caraballo L, Fernandez-Caldas E, Avjioglu A, Marsh DG, Lockey RF, et al. Nucleotide sequence analysis of a complementary DNA coding for a Blomia tropicalis allergen. J Allergy Clin Immunol. 1996; 98(5 Pt 1):932-937. [PubMed: 8939156]

9. Zakzuk J, Beneddetti E, Fernandez-Caldas E, Caraballo L. Blo t 12 isoforms are chitin binding allergens that induce airway inflammation. Allergy. 2013; 68:174-175.

10. Da Silva CA, Pochard P, Lee CG, Elias JA. Chitin Particles Are Multifaceted Immune Adjuvants. Am J Resp Crit Care. 2010; 182(12):1482-1491.

11. Reese TA, Liang HE, Tager AM, Luster AD, Van Rooijen N, Voehringer D, et al. Chitin induces accumulation in tissue of innate immune cells associated with allergy. Nature. 2007; 447(7140): 92-96. [PubMed: 17450126]

12. Chupp GL, Lee CG, Jarjour N, Shim YM, Holm CT, He S, et al. A chitinase-like protein in the lung and circulation of patients with severe asthma. New Engl J Med. 2007; 357(20):2016-2027. [PubMed: 18003958]

13. Dickey BF. Exoskeletons and exhalation. N Engl J Med. 2007; 357(20):2082-2084. [PubMed: 18003965]

14. Banerjee S, Weber M, Blatt K, Swoboda I, Focke-Tejkl M, Valent P, et al. Conversion of Der p 23, a New Major House Dust Mite Allergen, into a Hypoallergenic Vaccine. J Immunol. 2014; 192(10):4867-4875. [PubMed: 24733847]

15. King EM, Vailes LD, Tsay A, Satinover SM, Chapman MD. Simultaneous detection of total and allergenspecific IgE by using purified allergens in a fluorescent multiplex array. J Allergy Clin Immun. 2007; 120(5):1126-1131. [PubMed: 17825887]

16. Trombone APF, Tobias KRC, Ferriani VPL, Schuurman J, Aalberse RC, Smith AM, et al. Use of a chimeric ELISA to investigate immunoglobulin E antibody responses to Der $\mathrm{p} 1$ and Der $\mathrm{p} 2$ in mite-allergic patients with asthma, wheezing and/or rhinitis. Clinical and Experimental Allergy. 2002; 32(9):1323-1328. [PubMed: 12220471]

17. Osinski T, Pomes A, Majorek KA, Glesner J, Offermann LR, Vailes LD, et al. Structural Analysis of Der p 1-Antibody Complexes and Comparison with Complexes of Proteins or Peptides with Monoclonal Antibodies. J Immunol. 2015; 195(1):307-316. [PubMed: 26026055] 
18. Heymann PW, Chapman MD, Aalberse RC, Fox JW, Plattsmills TAE. Antigenic and StructuralAnalysis of Group-Ii Allergens (Der-F-Ii and Der-P-Ii) from House Dust Mites (Dermatophagoides Spp). J Allergy Clin Immun. 1989; 83(6):1055-1067. [PubMed: 2732406]

19. Mueller GA, Pedersen LC, Glesner J, Edwards LL, Zakzuk J, London RE, et al. Analysis of glutathione S-transferase allergen cross-reactivity in a North American population: Relevance for molecular diagnosis. J Allergy Clin Immunol. 2015; 136:1369-1377. [PubMed: 25930195]

20. Mueller GA, Gosavi RA, Krahn JM, Edwards LL, Cuneo MJ, Glesner J, et al. Der p 5 Crystal Structure Provides Insight into the Group 5 Dust Mite Allergens. Journal of Biological Chemistry. 2010; 285(33):25394-25401. [PubMed: 20534590]

21. Mueller GA, Edwards LL, Aloor JJ, Fessler MB, Glesner J, Pomes A, et al. The structure of the dust mite allergen Der $\mathrm{p} 7$ reveals similarities to innate immune proteins. J Allergy Clin Immun. 2010; 125(4):909-917. [PubMed: 20226507]

22. Schuurman J, Perdok GJ, Lourens TE, Parren PWHI, Chapman MD, Aalberse RC. Production of a mouse/human chimeric IgE monoclonal antibody to the house dust mite allergen Der $\mathrm{p} 2$ and its use for the absolute quantification of allergen-specific IgE. J Allergy Clin Immun. 1997; 99(4): 545-550. [PubMed: 9111501]

23. Avula-Poola S, Morgan MS, Arlian LG. Diet Influences Growth Rates and Allergen and Endotoxin Contents of Cultured Dermatophagoides farinae and Dermatophagoides pteronyssinus House Dust Mites. Int Arch Allergy Imm. 2012; 159(3):226-234.

24. Morgan MS, Arlian LG, Markey MP. Sarcoptes scabiei mites modulate gene expression in human skin equivalents. Plos One. 2013; 8(8):e71143. [PubMed: 23940705]

25. Li B, Dewey CN. RSEM: accurate transcript quantification from RNA-Seq data with or without a reference genome. BMC bioinformatics. 2011; 12:323. [PubMed: 21816040]

26. Grabherr MG, Haas BJ, Yassour M, Levin JZ, Thompson DA, Amit I, et al. Full-length transcriptome assembly from RNA-Seq data without a reference genome. Nat Biotechnol. 2011; 29(7):644-652. [PubMed: 21572440]

27. Minor W, Cymborowski M, Otwinowski Z, Chruszcz M. HKL-3000: the integration of data reduction and structure solution - from diffraction images to an initial model in minutes. Acta Crystallographica Section D-Biological Crystallography. 2006; 62:859-866.

28. Schneider TR, Sheldrick GM. Substructure solution with SHELXD. Acta Crystallographica Section D-Biological Crystallography. 2002; 58:1772-1779.

29. Otwinowski, Z. Isomorphous Replacement and Anomolous Scattering. In: Wolf, W.; Evans, PR.; Leslie, AGW., editors. Proceedings of the CCP4 Study Weekend Warrington, Darebury Laboratory; 1991.

30. Perrakis A, Morris R, Lamzin VS. Automated protein model building combined with iterative structure refinement. Nature Structural Biology. 1999; 6(5):458-463. [PubMed: 10331874]

31. Adams PD, Afonine PV, Bunkoczi G, Chen VB, Davis IW, Echols N, et al. PHENIX: a comprehensive Python-based system for macromolecular structure solution. Acta Crystallographica Section D-Biological Crystallography. 2010; 66:213-221.

32. Emsley P, Cowtan K. Coot: model-building tools for molecular graphics. Acta Crystallographica Section D-Biological Crystallography. 2004; 60:2126-2132.

33. Davis IW, Leaver-Fay A, Chen VB, Block JN, Kapral GJ, Wang X, et al. MolProbity: all-atom contacts and structure validation for proteins and nucleic acids. Nucleic Acids Research. 2007; 35:W375-W83. [PubMed: 17452350]

34. Ghosh D, Mueller GA, Schramm G, Edwards LL, Petersen A, London RE, et al. Primary Identification, Biochemical Characterization, and Immunologic Properties of the Allergenic Pollen Cyclophilin Cat r 1. Journal of Biological Chemistry. 2014; 289(31):21374-21385. [PubMed: 24939849]

35. Notredame C, Higgins DG, Heringa J. T-Coffee: A novel method for fast and accurate multiple sequence alignment. Journal of Molecular Biology. 2000; 302(1):205-217. [PubMed: 10964570]

36. Case, DA.; Babin, V.; Berryman, JT.; Betz, RM.; Cai, Q.; Cerutti, DS., et al. AMBER 14. San Francisco: University of California; 2014. 
37. Ivanciuc O, Midoro-Horiuti T, Schein CH, Xie LP, Hillman GR, Goldblum RM, et al. The property distance index PD predicts peptides that cross-react with IgE antibodies. Mol Immunol. 2009; 46(5):873-883. [PubMed: 18950868]

38. Celniker G, Nimrod G, Ashkenazy H, Glaser F, Martz E, Mayrose I, et al. ConSurf: Using Evolutionary Data to Raise Testable Hypotheses about Protein Function. Isr J Chem. 2013; 53(34):199-206.

39. Chan TF, Ji KM, Yim AK, Liu XY, Zhou JW, Li RQ, et al. The draft genome, transcriptome, and microbiome of Dermatophagoides farinae reveal a broad spectrum of dust mite allergens. J Allergy Clin Immunol. 2015; 135(2):539-548. [PubMed: 25445830]

40. Holm L, Kaariainen S, Rosenstrom P, Schenkel A. Searching protein structure databases with DaliLite v.3. Bioinformatics. 2008; 24(23):2780-2781. [PubMed: 18818215]

41. Suetake T, Tsuda S, Kawabata S, Miura K, Iwanaga S, Hikichi K, et al. Accelerated Publication Chitin-binding proteins in invertebrates and plants comprise a common chitin-binding structural motif. Journal of Biological Chemistry. 2000; 275(24):17929-17932. [PubMed: 10770921]

42. Kawabata S, Nagayama R, Hirata M, Shigenaga T, Agarwala KL, Saito T, et al. Tachycitin, a small granular component in horseshoe crab hemocytes, is an antimicrobial protein with chitinbinding activity. Journal of biochemistry. 1996; 120(6):1253-1260. [PubMed: 9010778]

43. Aboitiz N, Vila-Perello M, Groves P, Asensio JL, Andreu D, Canada FJ, et al. NMR and modeling studies of protein-carbohydrate interactions: Synthesis, three-dimensional structure, and recognition properties of a minimum hevein domain with binding affinity for chitooligosaccharides. Chembiochem. 2004; 5(9):1245-1255. [PubMed: 15368576]

44. Shen Y, Delaglio F, Cornilescu G, Bax A. TALOS plus : a hybrid method for predicting protein backbone torsion angles from NMR chemical shifts. Journal of Biomolecular Nmr. 2009; 44(4): 213-223. [PubMed: 19548092]

45. Doreleijers JF, Mading S, Maziuk D, Sojourner K, Yin L, Zhu J, et al. BioMagResBank database with sets of experimental NMR constraints corresponding to the structures of over 1400 biomolecules deposited in the Protein Data Bank. Journal of Biomolecular Nmr. 2003; 26(2):139146. [PubMed: 12766409]

46. Sharma D, Rajarathnam K. C-13 NMR chemical shifts can predict disulfide bond formation. Journal of Biomolecular Nmr. 2000; 18(2):165-171. [PubMed: 11101221]

47. Smith AM, Chapman MD. Reduction in IgE binding to allergen variants generated by site-directed mutagenesis: Contribution of disulfide bonds to the antigenic structure of the major house dust mite allergen Der p 2. Mol Immunol. 1996; 33(4-5):399-405. [PubMed: 8676891]

48. Takai T, Yokota T, Yasue M, Nishiyama C, Yuuki T, Mori A, et al. Engineering of the major house dust mite allergen Der f2 for allergen-specific immunotherapy. Nat Biotechnol. 1997; 15(8): 754-758. [PubMed: 9255789]

49. Benjamin DC, Berzofsky JA, East IJ, Gurd FR, Hannum C, Leach SJ, et al. The antigenic structure of proteins: a reappraisal. Annu Rev Immunol. 1984; 2:67-101. [PubMed: 6085753]

50. Garcia-Hernandez E, Zubillaga RA, Rojo-Dominguez A, Rodriguez-Romero A, Hernandez-Arana A. New insights into the molecular basis of lectin-carbohydrate interactions: a calorimetric and structural study of the association of hevein to oligomers of $\mathrm{N}$-acetylglucosamine. Proteins. 1997; 29(4):467-477. [PubMed: 9408944]

51. Tellam RL, Wijffels G, Willadsen P. Peritrophic matrix proteins. Insect Biochem Molec. 1999; 29(2):87-101.

52. Hales BJ, Martin AC, Pearce LJ, Laing IA, Hayden CM, Goldblatt J, et al. IgE and IgG anti-house dust mite specificities in allergic disease. J Allergy Clin Immun. 2006; 118(2):361-367. [PubMed: 16890759]

53. Pittner G, Vrtala S, Thomas WR, Weghofer M, Kundi M, Horak F, et al. Component-resolved diagnosis of house-dust mite allergy with purified natural and recombinant mite allergens. Clinical and Experimental Allergy. 2004; 34(4):597-603. [PubMed: 15080813]

54. Weghofer M, Thomas WR, Kronqvist M, Mari A, Purohit A, Pauli G, et al. Variability of IgE reactivity profiles among European mite allergic patients. Eur J Clin Invest. 2008; 38(12):959_ 965. [PubMed: 19021722] 
55. Arlian LG, Morgan MS, Neal JS. Dust mite allergens: ecology and distribution. Curr Allergy Asthma Rep. 2002; 2(5):401-411. [PubMed: 12165207] 


\section{Mite positive patients}

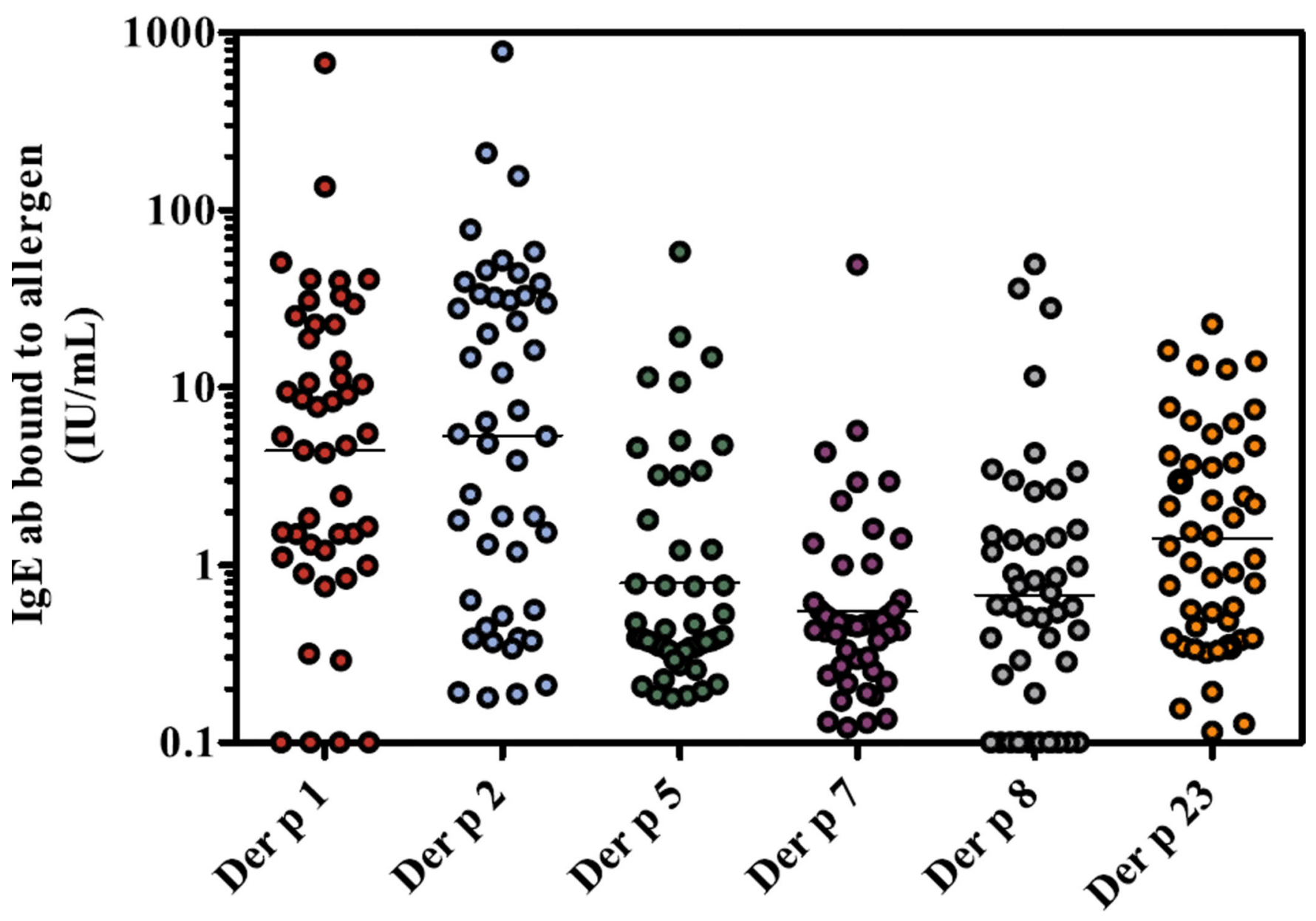

Figure 1.

Specific IgE against the six dust mite allergens Der p 1, Der p 2, Der p 5, Der p 7, Der $p 8$ and Der p $23(n=47)$. Horizontal bars represent the geometric means of the values. 


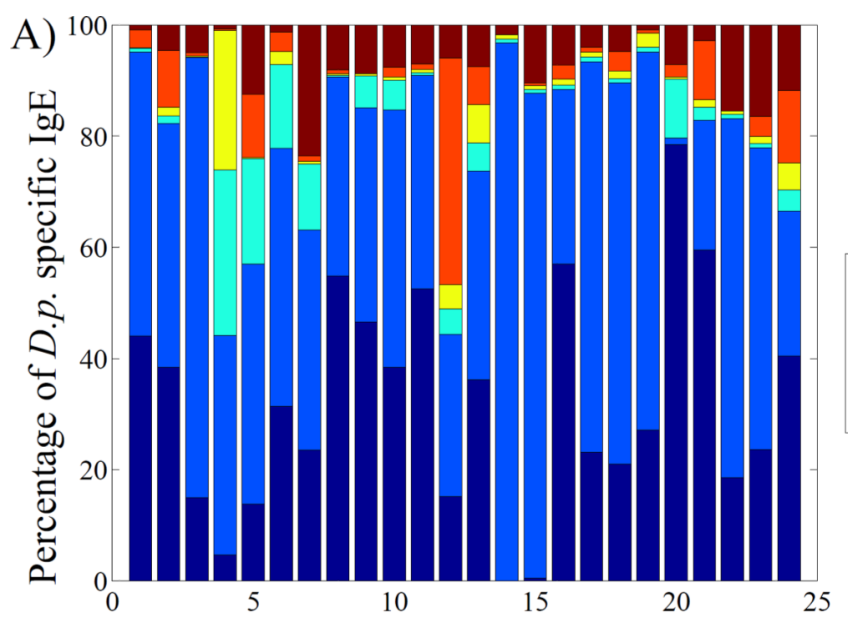

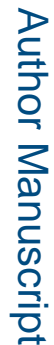

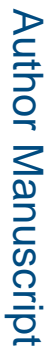

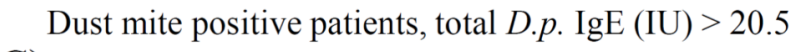

C)

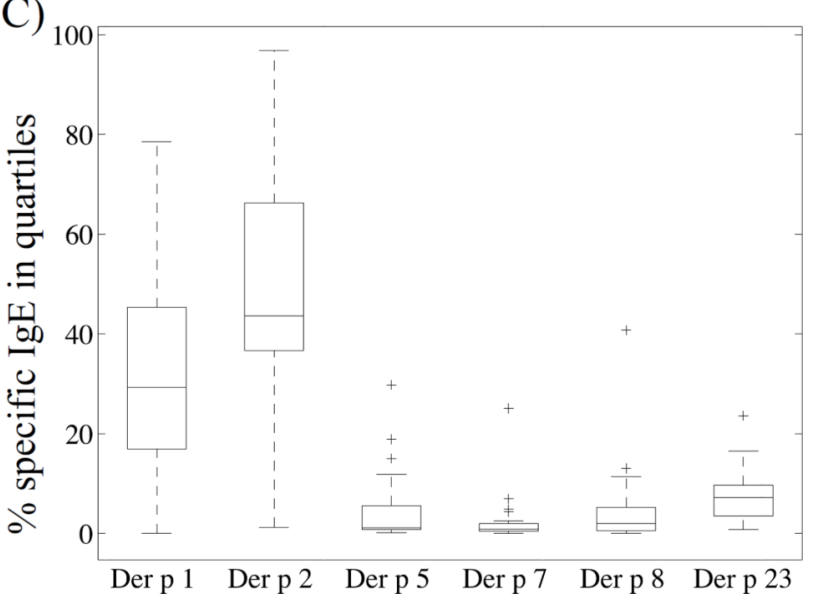

Figure 2.
B)

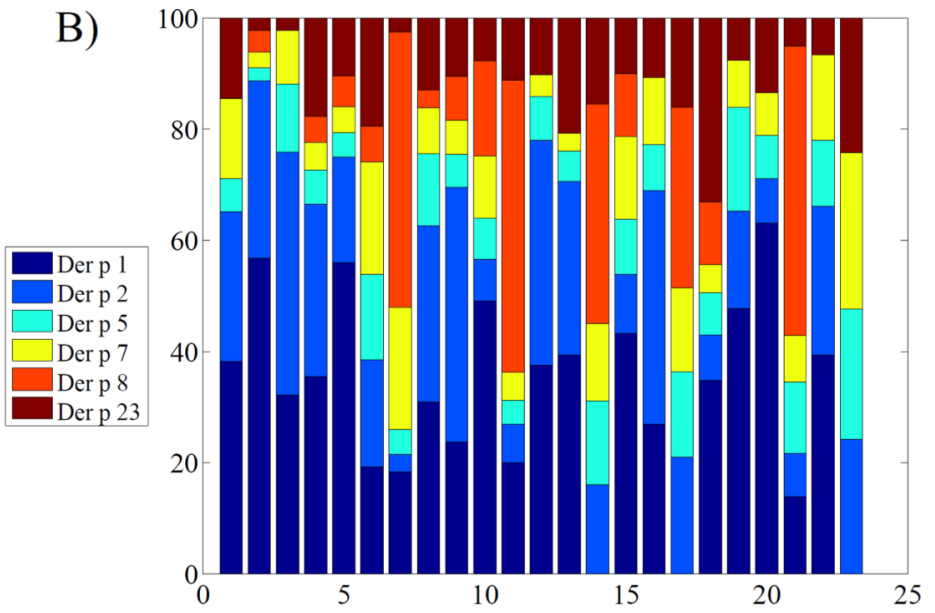

Dust mite positive patients, total D.p. $\operatorname{IgE}$ (IU) $<20.5$

D)

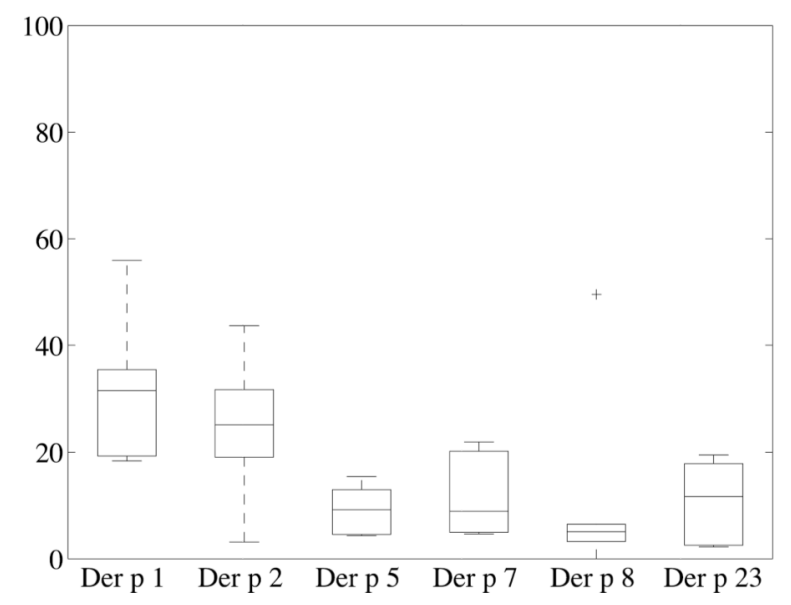

Percentages of allergen-specific IgE reactivity, A) \& B) percentages on a per patient basis. The colors are indicated in the legend for each allergen. C) \& D) Boxplot of average and quartile percentages for the two patient groups. A) \& C) Patients (n=23) selected based on the sum of IgE reactivity to the six allergens being higher than the median $20.5 \mathrm{IU} / \mathrm{mL}$, and B) $\boldsymbol{\&}$ D) for the remaining $\mathrm{n}=24$ patients. 
A)

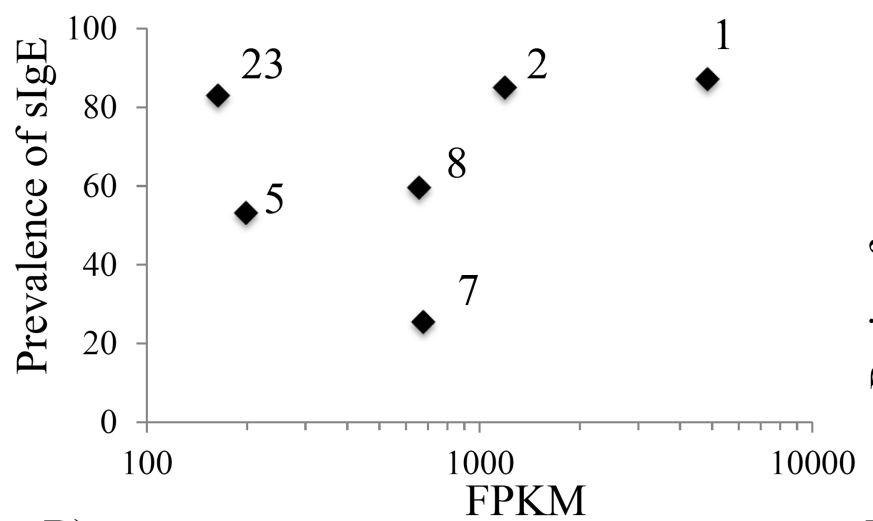

B)

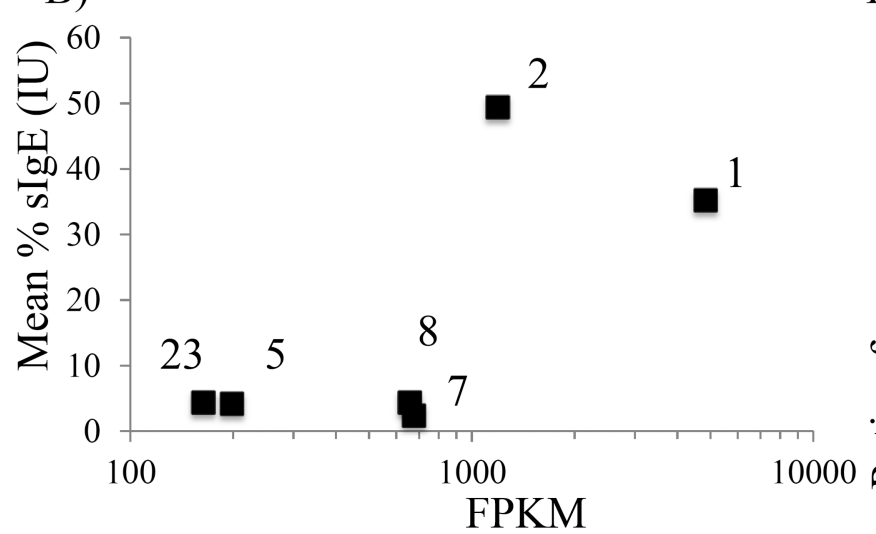

C)

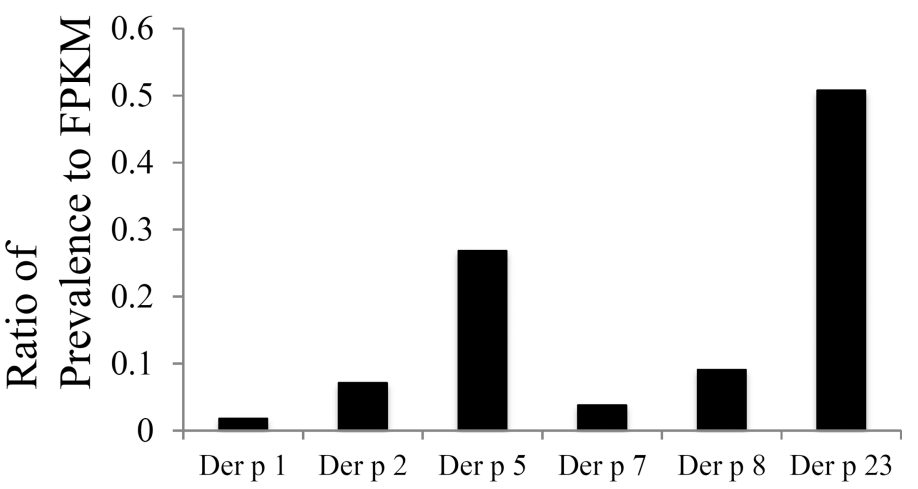

D)

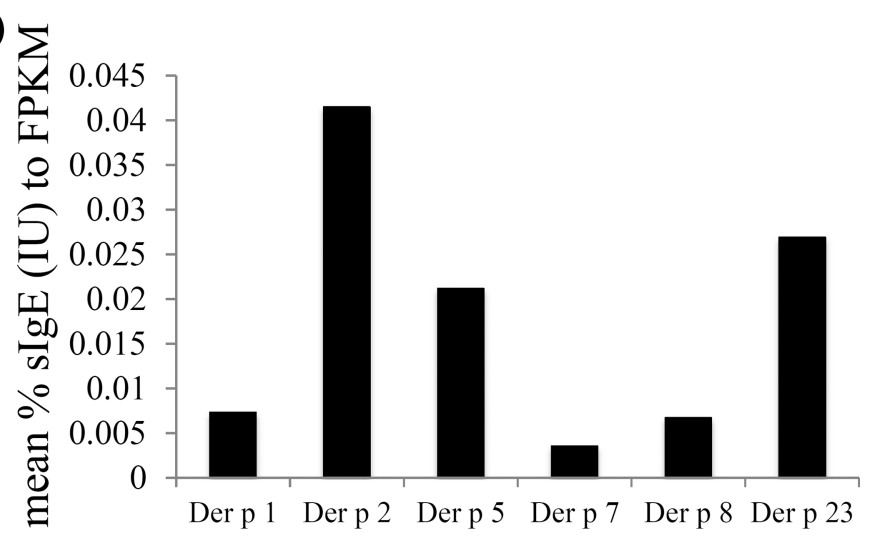

Figure 3.

Comparisons of relative prevalence and $\operatorname{sIgE}$ for Der $\mathrm{p} 1,2,5,7,8$, and 23 versus expression levels. A) and B) show prevalence and average sIgE respectively from Table 1 versus FPKM. C) and D) show the ratio of the prevalence or sIgE respectively to the FPKM for each allergen. 

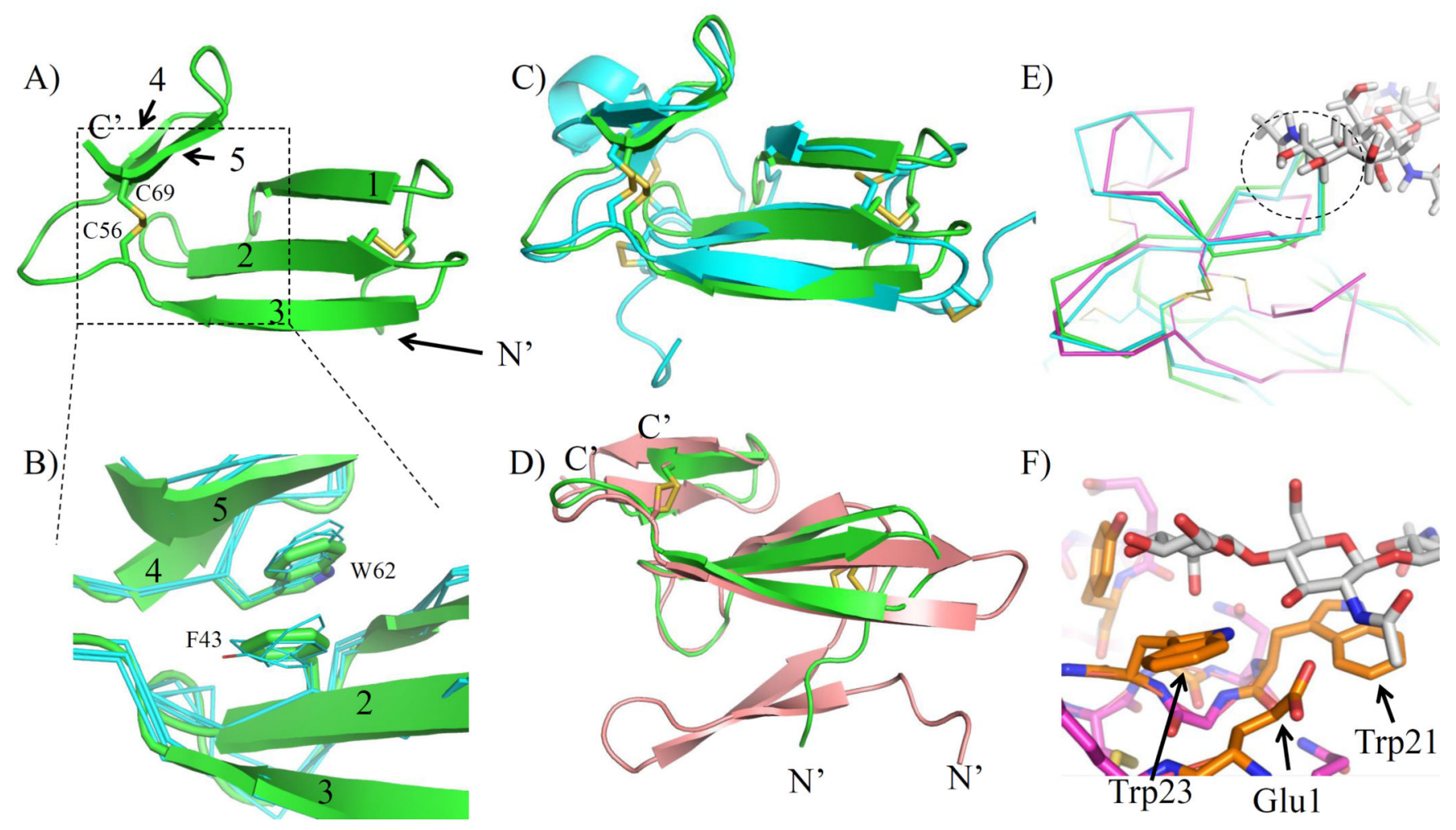

Figure 4.

Crystal structure of Der p 23 and comparisons to related proteins. A) Ribbon diagram of the crystal structure of chain A of Der p 23 showing the positions of the $\beta$-sheets and two disulfide bonds, pdb: 4ZCE. B) Structural comparison of Der p 23 (green) with related modeled proteins from $D$. farinae showing the aromatic stacking interaction between the two sheets. The specific models overlaid in panel B are: DEFA_019670, DEFA_041620, and DEFA_123860 (Der f 23). C) Alignment of Der p 23 (green) with tachychitin (PDB code: 1DQC, cyan); the latter has 4 disulfide bonds [41]. D) Alignment of Der p 23 (green) with Blo t 12 (PDB code: 2MFK, beige, unpublished). E) Alignment of Der $\mathrm{p} 23$ (green) and tachychitin (cyan) with a hevein domain (1T0W, magenta) bound to $\beta-1,4$ linked tri-n-acetyl glucosamine (gray stick representation) [43]. Dashed circle indicates a clash between Der p 23 and the hevein substrate. F) Residues important for hevein-glucosamine interaction are colored orange (1T0W). 
A)

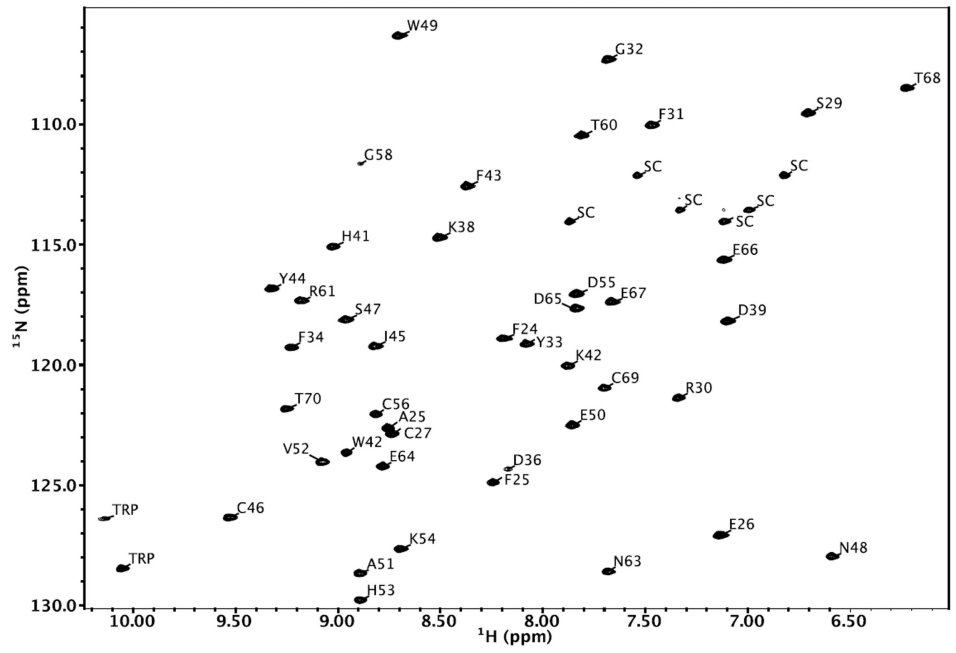

B)

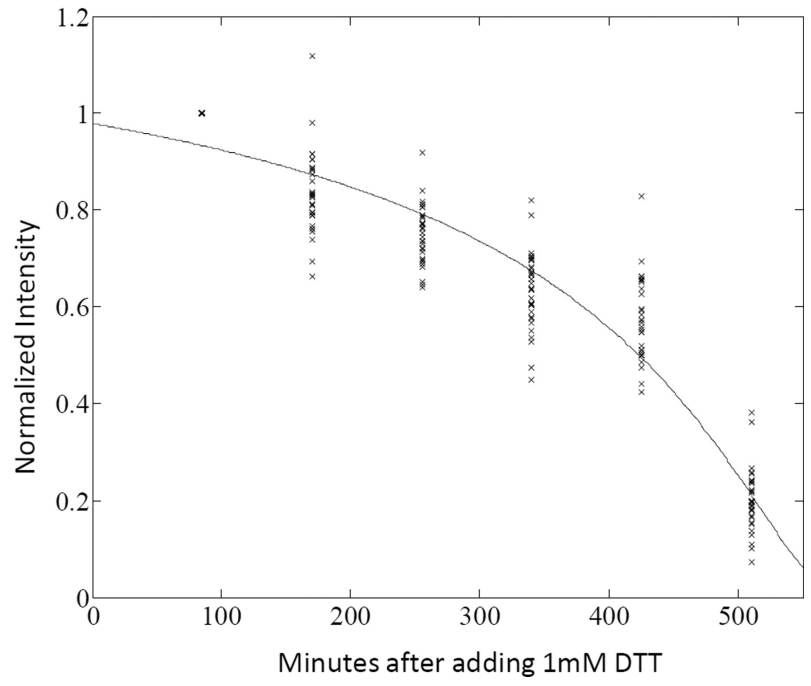

Figure 5.

Amide ${ }^{1} \mathrm{H}_{-}{ }^{15} \mathrm{~N}$ HSQC spectrum and intensity decay with addition of DTT. A) NMR assignments are annotated on the ${ }^{1} \mathrm{H}_{-}{ }^{15} \mathrm{~N}$ HSQC. TRP and SC indicate ambiguous assignment of Trp and Asn or Gln side chains. B) Decay of the intensity of the NMR signals after adding $1 \mathrm{mM}$ DTT. 

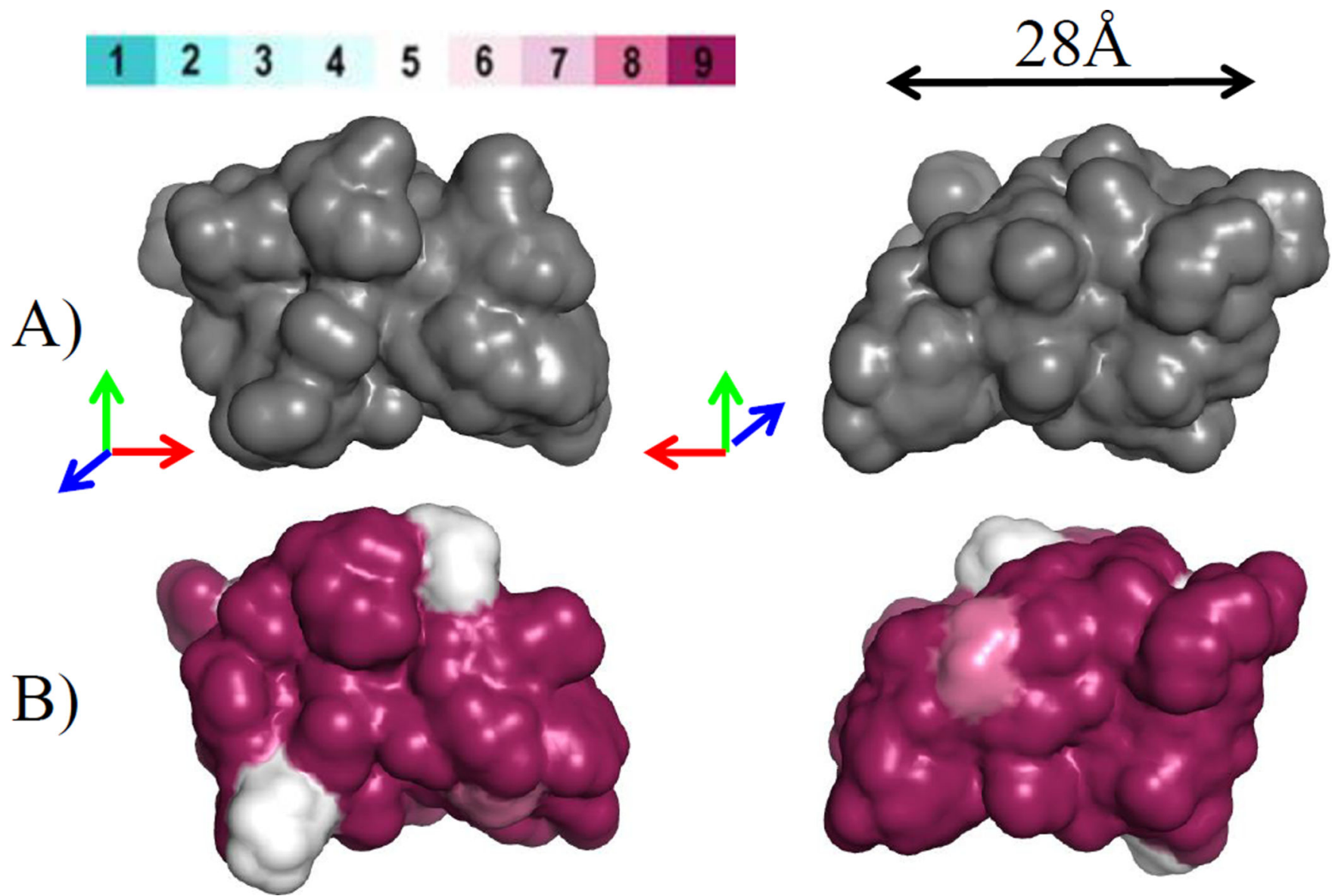

Figure 6.

Der p 23 structure and Der f 23 structural model. A) and B) show surface representations of Der p 23 and Der f 23 respectively. B) is colored based on the residues similarity to Der $\mathrm{p}$ 23 , using the color scale at the top where 1 (cyan) indicates very different and 9 (maroon) indicates identical residues. The two panels are rotated 180 degrees according to the arrow keys. 

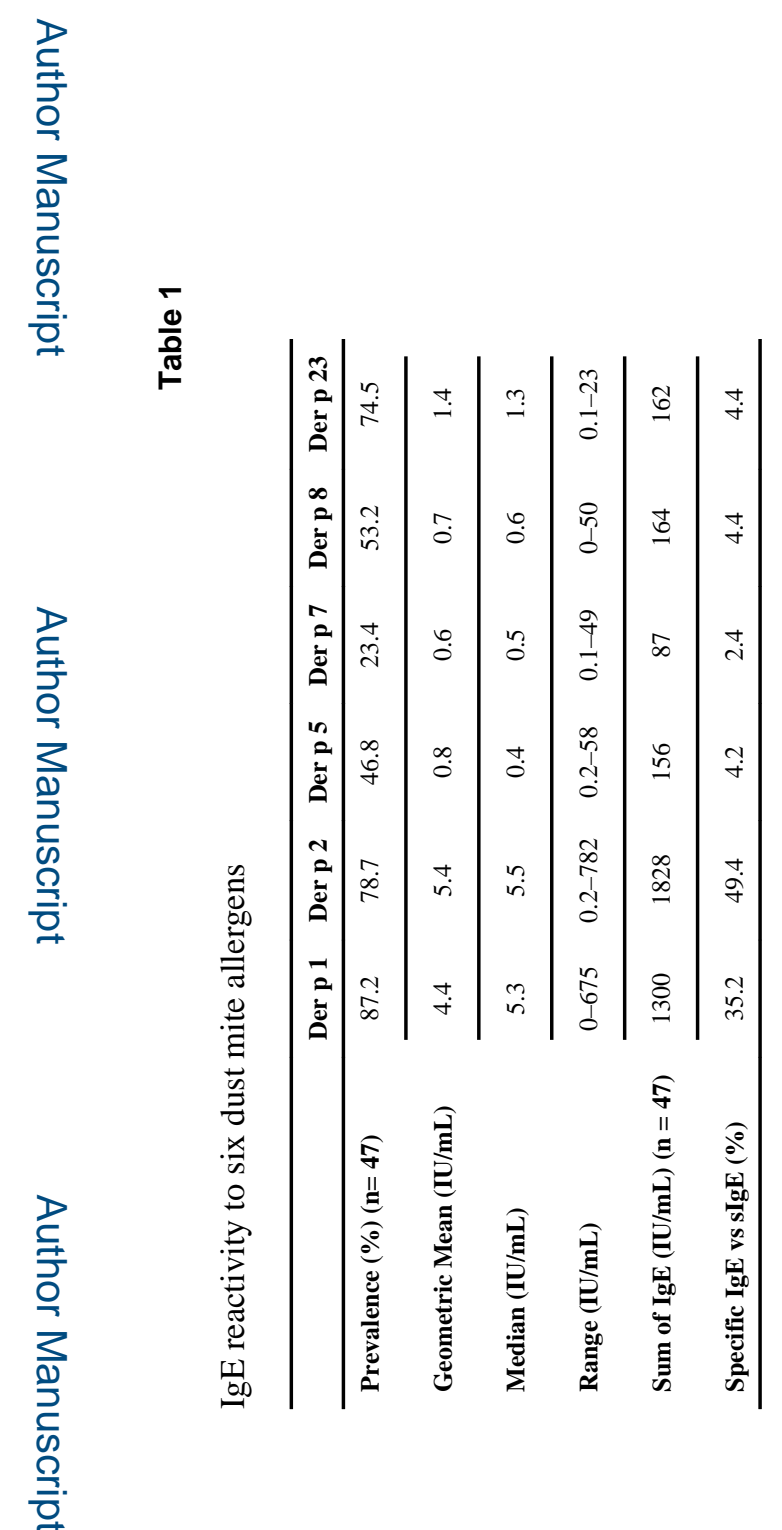

Clin Exp Allergy. Author manuscript; available in PMC 2017 February 01. 